The Social Sciences 7 (1): 9-15, 2012

ISSN: $1818-5800$

C) Medwell Journals, 2012

\title{
Knowledge, Attitude, Concept Mapping Usage and the Economics Subject Achievement among the Form 4 Students
}

\author{
Nor Aishah Buang and Choa Kam Foong \\ Faculty of Education, Universiti Kebangsaan Malaysia, \\ 43600 Bangi, Selangor DE, Malaysia
}

\begin{abstract}
The purpose of this study was to find out whether knowledge, attitude and concept mapping usage among the form four students have relationships with the Foundations of Economics subject achievement. The respondents consisted of 143 respondents from five selected schools in the district of Hulu Langat, Selangor. A survey design was used which employed a questionnaire to obtain the data. Descriptive statistics such as the mean, standard deviation, percentage, frequency and inferential statistics such as t-test, one-way ANOVA and Pearson correlation ( $\mathrm{r}$ ) were used to analyze the data. The findings showed that the respondents had moderately high level of knowledge, attitude and concept mapping usage of the Foundations of Economics subject. There was no significant difference in the level of knowledge, attitude and concept mapping usage based on gender and race. However, the male students used concept mappings in learning the subject matter more often than the female students. The one-way ANOVA showed a significant difference in the level of concept mapping knowledge among the students based on race. The Malay students had a better knowledge of concept mapping than the Chinese students. The students with high achievement had higher level of knowledge, attitude and concept mapping usage. The implication of this study is students need to learn to use concept mapping technique in order to do well in the subject matter.
\end{abstract}

Key words: Knowledge, attitude, concept mapping usage, economics subject, questionnaire, Malaysia

\section{INTRODUCTION}

According to the National Board of Examination Malaysia, the percentage of students passing the Foundations of Economics subject at the secondary schools continue to decrease from year to year. For example, the percentage of passing the subject matter was $73.0 \%$ in 1997 and continuously decreased to $63.3 \%$ in 2005. Reports by the Foundation of Economics subject panel at the district and state level stated that the low achievements in the subject matter were due to several reasons.

On the teacher side, inadequate teaching skills among the teachers due to lack of training in teaching the subject matter was among other reasons. On the students side, difficulty in understanding the concepts not interested in the subject matter and lack of motivation to learn were among the facts reported. In a study conducted by Hussin (1999) found out that another reason for the learning problems among the students was due to the way the economics textbooks' content was written which is dull and not attractive. According to the State Education Department of Pahang many students who sat for the national examination of the subject matter failed or obtained low grade. This was due to the fact that the questions asked in the examination were at application level which need a high level of thinking skills on the part of the students.

Larcombe (1985) stated that there are many reasons for learning difficulty among the school students such as their surroundings backgrounds weak in basic knowledge bad learning habits and learning approach. Among these reasons he pointed out that bad learning habits and inappropriate teacher's teaching approaches were the main ones for causing learning difficulty among the students.

A study done by Fathiah found out that teachers did not teach students the skills of searching, understanding, analyzing and using information. In addition, Fathiah pointed out teachers seldom taught students touse study skills and tools such as concept mapping, graphic organizers and mnemonics. Studies had shown that used of study tools among the students helped them to organize their learning and thus easy to understand (Hergenhahn and Olson, 2005). Concept mapping provides a visualization of the relationship among a set of

Corresponding Author: Nor Aishah Buang, Faculty of Education, Universiti of Kebangsaan Malaysia, 43600 Bangi, Selangor DE, Malaysia 
concepts and ideas which were related. Woolfolk (1995) stated that for students to be able to use concept mapping they must have some information on a concept categorize it and put it according to the required hierarchy. In describing a concept students must be able to expand its maps until it can be represented in the whole (Lian, 1997).

The concept mapping usage would become more interesting when the students did and use it in groups. Students could also share ideas to make it more interesting to be used. The use of concept mapping enables the students to become more active in searching for important content and facts for a topic or chapter. The forming of concept maps is not necessarily uniform among the members of a group or individuals. This is because the concept maps formed represented the understanding of the person towards the topic read by him or her (Novak, 1990).

It is a proven method in visualizing how the mind sees a certain topic. The building of concept mapping enables a person to reflect his or her knowledge of a subject. Concepts were typically enclosed in circles or boxes represented by words and relationships between concepts were represented by connecting lines that link them together. Words or simple phrases on the linking lines explain the relationships between the concepts. The main concept would have linking lines to (and from) a few other concepts to form a relationship web (White, 2007). The use of concept mapping has to do with the way, the human mind process information.

The Information processing model is a product of cognitive theory which observed how human mind took in information, organized it stored it for later use and then retrieved it when necessary from the memory. This was in line with the statement made by Borich and Tombari (1997) and Brynes (2001) which claimed that the Information processing model referred to human mental activities which receive, tore and retrieve information for use just like computer system. In addition, Banikowski and Mehring (1999) explained that the Information processing model was based on processed and interpretation of sensory data and the arrangement of such data into form which could be remembered.

The Information processing model involved inner structures which were regarded as information stores for the storage of information and a few cognitive processes of changing and moving from one store to another store (Eggen and Kauchak, 2001). On the other hand, Ausubel (1963) had proposed the Assimilation learning theory in which he differentiated the two main methods of cognitive learning namely meaningful learning and rote learning. Rote learning happened when new knowledge was combined in the students cognitive structure separately without any system. Thus, rote learning did not involve any deeper thinking. Individual who used rote learning could only retrieve new information but was not readily applied to new problem-solving situations because it was not connected with concepts already learned.

The method of information storage through rote learning would not last longer easily forgotten and the information likely to disappeared. Rote learning became the practice of students who did not have the correct and effective educational system. Hence, concept mapping was introduced to assist students in understanding and remembering more effectively without memorizing. Through concept mapping, students would notice that their learning became easier and students would be interested if any of the subjects were easy and interesting for revision. This would influence the student's performance as students felt motivated, high-spirited and interested in learning (Ausubel, 1963).

The purpose of the research carried out by the researcher was to investigate on knowledge, attitude and the practice of concept mapping usage and their correlation to Foundations of Economics subject achievement. A student's achievement was closely related to the learning method used. Therefore, this research obtained data on form 4 student's knowledge who took the subject of Foundations of Economics subject about concept mapping building. This research also obtained the visualization of students' attitude (readiness) and the practice of concept mapping usage in the learning of Foundations of Economics subject. To improve the achievement of Foundations of Economics subject, the appropriate learning approach should be utilized.

\section{MATERIALS AND METHODS}

The design of this research was a survey method. The population of this study consisted of form 4 students who chose the Foundation of Economics subject as an elective from the five schools in the District of Hulu Langat, Selangor. The five secondary schools were Engku Husain, Taman Jasmine II, Bandar Rinching, Tasik Kesuma and Kajang Utama. The size of the population was 475 students.

With reference to the principles proposed by Konting (2005) which stated that 30\% of the samples should be taken from the population, 143 students were selected. The random sampling method was used to select the samples. A questionnaire was developed based on the literature reviews and piloted twice for reliability and validity on 30 students. The reliability of the 
questionnaire based on the Cronbach alpha value was 0.79. Both descriptive and inferential statistics were used to analyze the data such as frequency, percentage, t-test, one-way ANOVA and Pearson correlation (r).

\section{RESULTS}

Profiles of the students: Table 1 shows the distribution of the respondents from each of the five selected schools. The total number of respondents was 143 students. The respondents from Taman Jasmine II secondary school were 42 (29.4\%) from Engku Husain were 27 (18.9\%) from Kajang Utama were 27 (18.9\%) from Tasik Kesuma were $25(17.5 \%)$ and Bandar Rinching were $22(15.4 \%)$. Based on gender there were 69 male respondents $(48.3 \%)$ and 74 female respondents $(51.7 \%)$ altogether.

Based on the different races there were 62 Malay respondents (43.4\%), 59 Chinese respondents (41.3\%) and 22 Indian respondents $(15.3 \%)$. With reference to the mid year examination results, 34 respondents $(23.8 \%)$ obtained low grade, 100 respondents $(69.9 \%)$ obtained average grade and only 9 respondents $(6.3 \%)$ obtained high grade.

The level of respondents' knowledge, attitude and concept mapping usage in learning the Foundations of Economics subject: Table 2 shows the level of the respondent's knowledge on concept mapping usage in the subject matter was moderately high (Mean = 3.63). Meanwhile, the level of attitude towards concept mapping usage in learning the subject matter was also moderately high $($ Mean $=3.57)$. The level of the respondent's concept mapping usage in learning the subject matter also moderately high $($ Mean $=3.21)$.

Table 1: The profiles of the respondents based on schools, gender, race and

\begin{tabular}{llcc}
\multicolumn{4}{c}{ mid year examination results } \\
Variables & Profile & Frequency (n) & Percent \\
\hline Schools & SMK Taman Jasmine II & 0.42 & 29.40 \\
& SMK Engku Husain & 0.27 & 18.90 \\
& SMK Kajang Utama & 0.27 & 18.90 \\
& SMK Tasik Kesuma & 0.25 & 17.50 \\
& SMK Bandar Rinching & 0.22 & 15.40 \\
Gender & Male & 0.69 & 48.30 \\
& Female & 0.74 & 51.70 \\
Race & Malay & 0.62 & 43.40 \\
& Chinese & 0.59 & 41.30 \\
& Indian & 0.22 & 15.30 \\
Mid year & $0-39 \%$ (low) & 0.34 & 23.80 \\
Examination & 40-74\% (average) & 100.00 & 69.90 \\
Result & $75-00 \%$ (high) & 0.09 & 6.03 \\
Total & & 143.00 & 100.00 \\
\hline
\end{tabular}

Table 2: The mean scores of Form 4 students' knowledge, attitude and practice towards concept mapping usage in learning subject the Foundations of Economics subject

\begin{tabular}{lcc}
\hline Variables & Mean \pm SD & Level \\
\hline Knowledge & $3.6342 \pm 0.80289$ & Moderately high \\
Attitude & $3.5697 \pm 0.68737$ & Moderately high \\
Usage & $3.2114 \pm 0.71744$ & Moderately high \\
\hline
\end{tabular}

The difference between the level of the respondents' knowledge, attitude and concept mapping usage in learning the Foundations of Economics subject based on gender: Table 3 shows no significant difference in the mean scores of form 4 students' knowledge towards concept mapping usage in learning the Foundation of Economics subject based on gender $(t=1.645, p=0.490)$. However, the mean score of male students (Mean = $2.6522, \mathrm{SD}=0.78264$ ) was higher than the mean score of female students $(\mathrm{Mean}=2.4324, \mathrm{SD}=0.81225$ ). Table 3 also shows no significant difference in the mean scores between male students' attitude and female students' attitude $(\mathrm{t}=0.508, \mathrm{p}=0.642)$ towards concept mapping usage in learning the Foundation of Economics subject. For male students, the mean score is $2.6667(\mathrm{SD}=0.57881)$ while the mean score for the female students, the mean score is $2.6081(\mathrm{SD}=0.69868)$.

The finding also shows no significant difference between the concept mapping usage of the male students and the female students $(t=0.911, p=0.239)$. The mean score for the male students is 2.4203 ( $\mathrm{SD}=$ 0.75549), meanwhile the mean score for the female students is 2.6081 ( $\mathrm{SD}=0.69868)$.

The difference between the level of form 4 students' knowledge, attitude and concept mapping usage in learning the Foundation of Economics subject based on race: To show the difference, the data was analyzed using one-way ANOVA shown in Table 4. Table 4 shows p-value which was smaller than the significant level $(\mathrm{F}=4.460, \mathrm{p}=0.013)$. This means that there was $\mathrm{a}$ significant difference in mean scores for the level of form

Table 3: t-test results for mean scores of knowledge, attitude and usage towards concept mapping in learning the Foundation of Economics subject based on gender

\begin{tabular}{llcccc}
\hline Variables & Gender & $\mathrm{n}$ & Mean \pm SD & t-test & Sig. \\
\hline Knowledge & Male & 69 & $2.6522 \pm 0.78264$ & 1.645 & 0.490 \\
& Female & 74 & $2.4324 \pm 0.68097$ & & \\
Attitude & Male & 69 & $2.6667 \pm 0.57881$ & 0.508 & 0.642 \\
& Female & 74 & $2.6081 \pm 0.69868$ & & \\
Usage & Male & 69 & $2.4203 \pm 0.75549$ & 0.911 & 0.239 \\
& Female & 74 & $2.3108 \pm 0.68097$ & & \\
\hline
\end{tabular}

Table 4: One-Way ANOVA to determine the difference between the level of form 4 students' knowledge, attitude and concept mapping usage in learning the Foundation of Economics subject based on race

\begin{tabular}{llrrrrrr}
\multicolumn{2}{c}{ race } & $\begin{array}{l}\text { Square root } \\
\text { of variance }\end{array}$ & $\begin{array}{r}\text { Sum of } \\
\text { squares }\end{array}$ & df & Mean & F-values & Sig. \\
Variables & Knowledge & Between groups & 5.483 & 2 & 2.742 & 4.460 & $0.013^{*}$ \\
& Within groups & 86.055 & 140 & 0.615 & & \\
& Total & 91.538 & 142 & & & \\
Attitude & Between groups & 1.241 & 2 & 0.621 & 1.319 & 0.271 \\
& Within groups & 65.852 & 140 & 0.470 & & \\
Usage & Total & 67.091 & 142 & & & \\
& Between ghroups & 0.615 & 2 & 0.308 & 0.594 & 0.553 \\
Total & Within groups & 72.476 & 140 & 0.518 & & \\
\hline
\end{tabular}

*Significant at the level of $\mathrm{p}<0.05$ 
The Soc. Sci., 7 (1): 9-15, 2012

Table 5: Scheffe's post-hoc ANOVA test for the level of knowledge based on race

\begin{tabular}{lcc}
\hline Race & Mean difference & \multicolumn{1}{c}{ Sig. } \\
\hline Malay-Chinese & 0.4046 & $0.020^{*}$ \\
Malay-Indian & 0.0279 & 0.990 \\
Chinese-Indian & -0.3767 & 0.161 \\
\hline *Significant at the level of $\mathrm{p}<0.05$ &
\end{tabular}

4 students' knowledge towards concept mapping usage in learning the Foundation of Economics subject based on race. Meanwhile, the finding also shows no significant difference in the mean scores of the students' attitude towards concept mapping usage in learning the subject matter based on race $(F=1.319, p=0.271)$. Table 4 shows there was no significant difference in the mean scores for the level of the students' concept mapping usage in learning the Foundation of Economics subject based on race $(\mathrm{F}=0.594, \mathrm{p}=0.553)$. On the other hand, Table 5 shows the result of Scheffe's post-hoc ANOVA test for looking at the significant difference in the mean scores for the level of form 4 students' knowledge towards concept mapping usage in learning the Foundation of Economics subject based on which race.

There was significant difference in the mean scores $(\mathrm{p}=0.020)$ between the Malay students and the Chinese students and there was no significant difference between the Malay and the Indian students $(\mathrm{p}=0.990)$ and the Chinese and the Indian students $(\mathrm{p}=0.161)$. This means that the Malay students' knowledge (Mean $=2.7093$ ) was higher than the Chinese students $(\mathrm{Mean}=2.3051)$.

The difference between the level of form 4 students' knowledge, attitude and concept mapping usage in learning the Foundation of Economics subject of based on achievement: Table 6 shows the results of the one-way ANOVA for testing the significance difference of the three variables based on achievement. There was significant difference in the mean scores of the form 4 students' knowledge towards concept mapping usage in the learning the subject matter based on achievement $(\mathrm{F}=20.895, \mathrm{p}=0.000$ ). The finding also shows significant difference in the mean scores of the form 4 students' attitude towards concept mapping usage in learning the subject matter based on achievement $(\mathrm{F}=14.283, \mathrm{p}=$ 0.000 ). There was significant difference in the mean scores of the form 4 students' concept mapping usage in learning the Foundations of Economics on achievement $(\mathrm{F}=31.755, \mathrm{p}=0.000)$.

Table 7 shows the result of Scheffe's post-hoc ANOVA test to look at the significant difference in the mean scores of the form 4 students' knowledge, attitude and concept mapping usage based the level of achievements. Based on Table 7, there was significant difference in the mean scores at the level of $\mathrm{p}<0.05$ for
Table 6: One-way ANOVA to determine the difference between the level of form 4 students' knowledge, attitude and the practice towards concept mapping usage in learning the Foundations of Economics subject based on achievement

\begin{tabular}{lllrrrr}
\hline \multirow{2}{*}{ Variables } & $\begin{array}{l}\text { Square root } \\
\text { of variance }\end{array}$ & $\begin{array}{l}\text { Sum of } \\
\text { squares }\end{array}$ & df & Mean $^{2}$ & F-value & Sig. \\
\hline Knowledge & Between groups & 21.043 & 2 & 10.522 & 20.895 & $0.000^{*}$ \\
& Within groups & 70.495 & 140 & 0.504 & & \\
& Total & 91.538 & 142 & & & \\
Attitude & Between groups & 11.372 & 2 & 5.686 & 14.287 & $0.000^{*}$ \\
& Within groups & 55.719 & 140 & 0.398 & & \\
& Total & 67.091 & 142 & & & \\
Usage & Between groups & 22.801 & 2 & 11.405 & 31.755 & $0.000^{*}$ \\
& Within groups & 50.281 & 140 & 0.359 & & \\
\hline
\end{tabular}

*Significant at the level of $\mathrm{p}<0.05$

Table 7: Scheffe's post-hoc ANOVA for the level of knowledge, attitude and practice based on achievement

\begin{tabular}{llcc}
\hline Variables & Achievement & Mean difference & Sig. \\
\hline Knowledge & Low-average & -0.7682 & $0.000^{*}$ \\
& Low-high & -1.4216 & $0.000^{*}$ \\
Attitude & Average-high & -0.6533 & $0.033^{*}$ \\
& Low-average & -0.5141 & $0.000^{*}$ \\
& Low-high & -1.1275 & $0.000^{*}$ \\
Usage & Average-high & -0.6133 & $0.022^{*}$ \\
& Low-average & -0.8635 & $0.000^{*}$ \\
& Low-high & -1.3235 & $0.000^{*}$ \\
& Average-high & -0.4600 & 0.092 \\
\hline
\end{tabular}

*Significant at the level of $\mathrm{p}<0.05$

the level of knowledge on concept mapping usage of students with low achievement and average achievement of students with low achievement and high achievement and of students with average achievement and high achievement. This shows that students with high achievement possessed high average level of knowledge of concept mapping usage (Mean = 3.3333), students with average achievement possessed low average level of knowledge of concept mapping usage $($ Mean $=2.6800$ ) and students with low achievement possessed low level of knowledge of concept mapping usage (Mean =1.9118). Based on Table 7, there was significant difference in the mean scores at the level of $\mathrm{p}<0.05$ for the level of attitude towards concept mapping usage of students with low achievement and average achievement of students with low achievement and high achievement and of students with average achievement and high achievement. This shows that students with high achievement possessed high level of attitude towards the concept mapping usage (Mean = 3.3333). Meanwhile, the students with average achievement $($ Mean $=2.7200)$ and students with low achievement $($ Mean $=2.2059)$ possessed low average level of attitude towards concept mapping usage. Table 7 also shows significant difference in the mean scores at the level of $p<0.05$ for the level of concept mapping usage of students with low achievement and average achievement and of students with low achievement and high achievement. This shows that the means of the level of 
Table 8: Correlations (r-values) between knowledge, attitude and practice with students achievement levels

\begin{tabular}{lcc}
\hline Correlation & r-values & Sig. \\
\hline Knowledge with students' achievement & 1.0 & $0.000^{*}$ \\
Attitude with students' achievement & 1.0 & $0.000^{*}$ \\
Practice with students' achievement & 1.0 & $0.000^{*}$ \\
\hline
\end{tabular}

*Significant at the level of $\mathrm{p}<0.05$

students with low achievement $(\mathrm{Mean}=1.6765)$ was lower than students with average achievement $($ Mean $=2.5400)$ and students with high achiev ement $($ Mean $=3.0000)$.

Knowledge, attitude and the practice of concept mapping usage and their correlation to Foundations of Economics subject achievement among form 4 students: Table 8 shows the results of the r-value obtained from the Pearson correlation coefficient analysis. It shows that knowledge, attitude and usage of concept mapping has a significant correlation at the level of 0.05 with the students' achievement levels. Table 8 shows that the r-value for knowledge, attitude and concept mapping usage with students' achievement levels was 1.0. This shows a very perfect relationship between knowledge, attitude and concept mapping usage with students' achievement levels. The positive r-values shows that the higher the mean scores of knowledge, attitude and concept mapping usage, the higher the students' achievement level.

\section{DISCUSSION}

The finding of this study shows that the level of form 4 students' knowledge towards concept mapping usage was moderately high (Mean $=3.6342$ ). This proves that students had been exposed with the concept mapping before and how to use the technique in their learning experiences. In other words, the use of concept mapping was not new to them. This finding is supported by a study conducted by Rohaya Jusoh (2006). She also found out that the level of students' knowledge on the concept mapping was moderately high (Mean $=3.58$ ). The finding also shows that the students had positive attitude towards the concept mapping usage (Mean = 3.5697) which was of the moderately high. This finding is supported by Azizah and Mat studies which found that students had a positive attitude towards concept mapping usage in their learning activities. In Azizah's study she found that the mean score of the level of concept mapping learning acceptance was 3.637. Ausubel (1963) in the Assimilation learning theory explained that learning will be effective and meaningful if the students are able to relate what they have just learnt with their previous knowledge. The information transfer could happen in many ways and through various techniques. More important here was the attitude towards and practice of active thinking skills. Ausubel emphasized that a positive attitude would promote frequent practice and thus become a good habit for the students. The combination of attitude, knowledge and a clear visualization of concept mapping technique would encourage the students to form their own concept maps for any topics of a subject matter. The students' academic achievement would increase through the frequent use of concept mapping in their learning activities. According to Zaidatol and Habibah, attitude and positive acceptance towards concept mapping among the students are vital elements for using them more frequently. In terms of concept mapping usage, the students who used concept mapping techniques in their larning process is moderately high (Mean $=3.2114$ ). The mean score infers that the students have good level of knowledge and positive attitude towards concept mapping technique. However, the finding of this study was in contrast with Rohaya Jusoh's study which shows that the level of students' concept mapping usage in their learning activities was low. This shows that students not necessarily would use concept mapping in their learning activities, although they have good knowledge about it. Only a small number of the students used it as a learning strategy despite of many had the knowledge and were exposed to its usage and its effectiveness.

The results of this study also shows that there is no significant difference in the level of students' knowledge about concept mapping based on gender. This explains that the gender factor does not influence the level of students' knowledge on concept mapping. However, the mean score of male students (Mean $=2.6522$ ) was higher than the mean score of female students $($ Mean $=2.4324)$ which implies that the male students knows better about the concept mapping than the female students. The t-test results on the level of students' attitude based on gender showed no significant difference towards attitude on concept mapping usage among male and female students even though again the mean score of male students (Mean $=2.6667)$ was higher than the mean score of female students $($ Mean $=2.6081)$. This study also found that there is no significant difference between male and female students' usage of concept mapping. However, there is a slight difference in the mean score of male students' usage of concept mapping compares to the female students. In this case, Rohaya Jusoh also found that there was no significant difference between the level of knowledge, attitude and concept mapping usage in learning the Commerce subject based on gender. The finding shows that there is a significant difference in terms of knowledge about concept mapping based on the different races such as the Malay, Chinese and Indians. 
Scheffe's post-hoc ANOVA test shows that there is a significant difference between the Malays and the Chinese. The mean score of the Malay students (Mean = 2.7093) was higher than the mean score of the Chinese students $($ Mean $=2.3051$ ). There was no significant difference in the mean scores for the level of students' attitude towards concept mapping usage based on race The mean score of the Malay students $($ Mean $=2.7079)$ was higher than the mean score of the Chinese students $($ Mean $=2.5254)$ and Indian students $($ Mean $=2.4073)$. All races have moderately low level of attitude towards concept mapping usage in the subject matter. The finding also shows no significant difference in the mean scores for the level of form 4 students' practice towards concept mapping usage in the learning of Foundations of Economics subject based on race. The mean score of Malay students (Mean $=2.4032$ ) was similar to the mean score of Chinese students (Mean $=2.2881)$ and Indian students (Mean $=2.4545$ ). All the form 4 students regardless of race possessed low average level of practice towards concept mapping usage in the learning of Foundations of Economics subject.

The difference between the level of form 4 students' knowledge, attitude and practice towards concept mapping usage in the learning of Foundations of Economics subject based on achievement: The research finding shows that there were significant differences in the mean scores for the level of form 4 students' knowledge towards concept mapping usage in the learning of Foundations of Economics subject based on achievement. The result of Scheffe's post-hoc ANOVA test shows that there were differences in the level of knowledge of students with low achievement and average achievement of students with low achievement and high achievement and of students with average achievement and high achievement. The mean score of students with high achievement (Mean = 3.3333) was higher than the mean score of students with average achievement (Mean $=2.6800$ ) and the mean score of students with low achievement $($ Mean $=1.9118)$. This shows that students with high achievement possessed high average level of knowledge, students with average achievement possessed low average level of knowledge and students with low achievement possessed low level of knowledge. The analysis also shows that there is no significant difference in the mean scores of the form 4 students' attitude towards concept mapping usage based on achievement. The analysis also shows that there were significant differences in the mean scores for the level of form 4 students' practice towards concept mapping usage in the learning of Foundations of Economics subject based on achievement. The result of Scheffe's post-hoc ANOVA test shows that there was significant difference in mean scores for the students with low achievement and average achievement and for the students with low achievement and high achievement. The mean score of the students with low achievement (Mean $=1.6765)$ was lower than the students with average achievement (Mean $=2.5400)$ and students with high achievement (Mean $=3.0000)$. However, there was no significant difference in mean scores for the level of students' practice towards concept mapping usage between the students with average achievement and high achievement. This showed that the students with average achievement high achievement possessed the similar level of practice. In a study done by Hussin (1999) who used experimental design on 135 students showed that the students who were taught using concept mapping technique scored better for questions of lower order thinking skills. Azizah used the same experimental design on 58 form 1 students found that there was a significant difference on the level of students' achievement between the group of students who received teaching using concept mapping technique and the group of students who received teaching using traditional method. The group of students who received teaching using concept mapping technique scored better compared to the group of students who received teaching using traditional method.

Knowledge, attitude and the practice of concept mapping usage and their correlation to Foundations of Economics subject achievement among form 4 students: The finding also shows that there was significant difference between knowledge, attitude and the practice of concept mapping usage and the achievement among the students. The analysis showed a very strong correlation $(\mathrm{r}=1.0)$. This meant that the students who obtained excellent achievement was due to the fact that they had the knowledge on concept mapping usage ready to accept concept mapping as a learning technique and practice concept mapping in their learning process. The students who were skilled and able to form their own concept maps would be able to use the learning skills available in a more effective way. The students were able to understand and remember the facts or the important content easily and hence would be able to improve the achievement in Foundations of Economics subject or in other subjects. The research of Fathiah, Mat and Wahidin proved the effectiveness of concept mapping usage separately in their researchers. However, the finding of this research was in contrast with the finding of the research of Rohaya Jusoh. The research finding on the relationship 
between students' achievement and the knowledge of concept mapping usage showed that there was no relationship between the students' achievement and previous knowledge on concept mapping and its effectiveness. The students who possessed only the knowledge on concept mapping technique would not be able to practice it if they did not have the skills of forming and creating their own concept maps. This was because the concept maps formed by students were from their knowledge and understanding of the topics that they learnt. The knowledge on concept mapping technique could not prove that the students were able to form or create concept maps using concept mapping technique. Also, the ability to form concept maps did not mean that the students were actually using the concept maps.

\section{CONCLUSION}

Teachers as the nearest role models for the students should portray the best examples for their students. The teachers' behaviours were sometimes set as examples, intensifiers or spirit lifters by some of the students. The use of concept mapping among teachers was the best beginning point for the concept mapping usage. The teachers should not just simply give instruction and guidance without practicing the concept mapping on their own. It was undeniable that there were teachers who fully used concept mapping in their teaching and learning process in schools but the number is too small if compared to the number of in-service teachers as a whole. Learning techniques give positive effect to the learning process. Students have to identify effective learning techniques to be used and to be practiced in their learning process.

This research was carried out to identify the knowledge, attitude and the practice of concept mapping usage and their relationships to the Foundation of Economics subject achievement among form 4 students. The concept mapping usage as a tool of learning process requires knowledge and skills in forming concept maps. Hence, this research finding is hoped to encourage the use of concept mapping technique as a tool of Creative and Critical Thinking Skills (CCTS) in the students' learning process. This research also hopes to increase the number of research among the students in other subjects.

\section{REFERENCES}

Ausubel, D.P., 1963. The Psychology of Meaningful Learning. Vol. 3, Grune and Stratton Inc., New York.

Banikowski, A.K. and T.A. Mehring, 1999. Strategies to enhance memory based on brain-research. Focus Exceptional Children, 32: 1-16.

Borich, G.D. and M.L. Tombari, 1997. Educational Psychology a Contemporary Approach. Longman, New York.

Brynes, J.P., 2001 . Cognitive Development and Learning in Instructional Contexts. Allyn and Bacon, Boston.

Eggen, P. and D. Kauchak, 2001. Educational Psychology Windows on Classrooms. Prentice Hall, New Jersey.

Hergenhahn, B.R. and M.H. Olson, 2005. An Introduction to Theories of Learning. Edisi ke-7. Pearson Education, New Jersey.

Hussin, M., 1999. The contribution in a knowledge mapping tecnicque to student understanding of economic tests. Ph.D. Tesis, University of Wales, Cardiff.

Larcombe, T., 1985. Mathematical Learning Difficultion in the Secondary School: Pupil Needs and Teacher Roles. Open University Press, Multon Keynes, PA., ISBN: 9780335150205 , Pages: 117.

Lian, M.W.S., 1997. The concept map: A tool for learning science concept and understanding cognitive process of pre service teachers. Tesis Sarjana Psikologi, Universiti Malaysia Sarawak.

Novak, J.D., 1990. Concept map and vee diagrams: Two metacognitive tools facilitate meaningful learning. Learn. Sci., 19: 29-52.

White, H., 2007. How to construct concept mapping. Department of Chemistry and Biochemistry, University of Delaware.

Woolfolk, A.E., 1995. Educational Psychology. Allyn and Bacon, Pearson, Boston, MA. 